\title{
Increased intercellular adhesion molecule-1 immunoreactivity in the sclera-choroid complex in hypercholesterolemia experimental model
}

\author{
Aumento da imunorreatividade da molécula de adesão intercelular-1 \\ na esclera e coroide em modelo experimental de hipercolesterolemia
}

Rogil José de Almeida Torres ${ }^{1}$, Lucia de Noronha², Regiane do Rocio de Almeida Torres ${ }^{3}$, Seigo Nagashima ${ }^{4}$, Caroline Luzia de Almeida Torres ${ }^{5}$, Andréa Luchini ${ }^{6}$, Robson Antônio de Almeida Torres ${ }^{5}$, Leonardo Brandão Précoma ${ }^{7}$, Dalton Bertolim Précoma ${ }^{8}$

\begin{abstract}
Objective: The aim of this study is to investigate the expression of the intercellular adhesion molecule 1 (ICAM-1) in the sclera and choroid of hypercholesterolemic rabbits. Methods: New Zealand rabbits were divided into two groups: the normal diet group (NG), with 8 rabbits (8 eyes), was fed a standard rabbit diet for 4 weeks; the hypercholesterolemic group (HG), with 13 rabbits (13 eyes), was fed a $1 \%$ cholesterol- enriched diet for 8 weeks. Total serum cholesterol, triglyceride, HDL cholesterol and fasting blood glucose exams were performed at the start of the experiment and at the euthanasia time. HG and NG animals were euthanized after 8th week and 4th week, respectively. Their eyes were stained with hematoxylin-eosin and underwent histological, histomorphometric and immunohistochemical analyses with ICAM-1 antibody. Results: The diet has induced a significant increase in total cholesterol and triglyceride levels in HG when compared with NG $(p<0.001)$. The histological analysis with hematoxylin-eosin revealed a large number of macrophages in the HG sclera-choroid complex. Moreover, a significant increase in the HG sclera and choroid thickness was observed in relation to NG ( $p<0.001)$. There was a significant increase in the ICAM-1 expression in HG sclera and choroid in relation to NG. Conclusion: This study has revealed that the hypercholesterolemic diet induces an increase in the ICAM-1 expression in the rabbits' sclera and choroid.
\end{abstract}

Keywords: Cholesterol;Cell adhesion molecules; Macrophages; Choroid; Sclera; Macular degeneration

\section{RESUMO}

Objetivo: O objetivo deste trabalho é avaliar a expressão da molécula de adesão intercelular-1 (ICAM-1) na esclera e coroide de coelhos hipercolesterolêmicos. Métodos: Coelhos New Zealand foram organizados em dois grupos: GN (grupo dieta normal), composto por 8 coelhos ( 8 olhos), recebeu ração padrão para coelhos, durante 4 semanas; GH (grupo hipercolesterolêmico), composto por 13 coelhos (13 olhos), recebeu dieta rica em colesterol a 1\% por 8 semanas. Foi realizada a dosagem sérica de colesterol total, triglicerídeos, HDL colesterol, glicemia de jejum no início do experimento e no momento da eutanásia. Ao final da $4^{\mathrm{a}}$ semana para o GN e $8^{a}$ semana para o GH foi realizada a eutanásia dos animais. Os olhos foram corados com hematoxilina-eosina e submetidos à análise histológica, histomorfométrica e imunohistoquímica com o anticorpo ICAM-1. Resultados: Observou-se significativo aumento do colesterol total e triglicerídeos do $\mathrm{GH}$ em relação ao $\mathrm{GN}(\mathrm{p}<0,001)$. A avaliação histológica com hematoxilina eosina revelou grande quantidade de macrófagos no complexo esclero-coroidal do GH. No GH constatou-se significativo aumento da espessura da esclera e coroide em relação ao GN $(\mathrm{p}<0,001)$. Houve significativo aumento da expressão da ICAM-1 na esclera e coroide dos animais do GH em relação ao GN ( $<<0,001)$. Conclusão: Este estudo demonstra que a dieta hipercolesterolêmica induz ao aumento da expressão da ICAM-1 na esclera e coroide de coelhos.

Descritores: Colesterol; Moléculas de adesão celular; Macrófagos; Coroide; Esclera; Degeneração macular

\footnotetext{
${ }^{1}$ Postdoctoral Programme, Pontifical Catholic University of Paraná, Curitiba/PR, Brazil;

2 Pontifical Catholic University of Paraná, Curitiba/PR, Brazil;

${ }^{3,4}$ Medical School of the Pontifical Catholic University of Paraná, Curitiba/PR, Brazil;

${ }^{5}$ Positivo University, Curitiba/PR, Brazil;

${ }^{6}$ Curitiba Ophthalmic Centre, Curitiba/PR, Brazil;

${ }^{7}$ Angelina Caron Hospital, Campina Grande do Sul/PR, Brazil;

${ }^{8}$ Pontifical Catholic University of Paraná, Curitiba/PR, Brazil;
}

Study conducted in the postgraduate unit of the Pontifical Catholic University of Paraná and the Angelina Caron Hospital (Campina Grande do Sul/PR).

The authors declare no conflict of interest.

Received for publication 17/12/2013 - Aceppted for 26/02/2014.

Rev Bras Oftalmol. 2014; 73 (4): 210-5 


\section{INTRODUCTION}

$\mathbf{P}$ athological intraocular neovascularisation is a complication that usually leads to blindness. Conditions associated with intraocular neovascularisation include retinopathy of prematurity, diabetic retinopathy, neovascular glaucoma, and age-related macular degeneration (AMD). AMD is a multifactorial disease that can be triggered by genetic, environmental, demographic, dietary, clinical, ocular, and lifestyle factors ${ }^{(1,2)}$.

For decades, AMD was attributed to excessive, pathological accumulation of lipids in Bruch's membrane due to a dysfunction of retinal pigment epithelium (RPE) cells ${ }^{(3)}$. More recently, the role of vascular endothelial growth factor (VEGF) in subretinal neovascularisation was clarified, which was critical to better understand the causes of AMD. As a result, major studies have been conducted to identify the mechanisms and the main cells responsible for releasing VEGF. Previous experimental and clinical studies aiming to identify the causes and cures for other organ diseases had demonstrated that hypoxia is the main stimulus for VEGF release ${ }^{(4)}$, thus helping understand the formation of the subretinal neovascular network seen in exudative $\mathrm{AMD}^{(1)}$. However, angiogenesis is a complex multi-stage process that involves not only growth factors, but also adhesion molecules and inflammatory cytokines, both of which have a key role in the process ${ }^{(5,6)}$.

Intercellular adhesion molecule 1 (ICAM-1), or CD54, is a glycoprotein of the immunoglobulin superfamily. Similarly to other adhesion molecules, ICAM-1 is present in leukocytes and endothelial cells and participates in leukocyte recruitment to injured or inflamed tissue ${ }^{(7)}$. A study performed in human donor eyes that aimed to assess ICAM-1 distribution in the choriocapillaris found a greater concentration of this immunoglobulin in the macula, as opposed to the peripheral region $^{(8)}$. This finding suggests a higher susceptibility of the macula to trafficking of immune cells such as macrophages, which helps explain the higher incidence of subretinal neovascular membrane in this region. In addition to producing $\operatorname{VEGF}^{(9)}$, macrophages are also a source of inflammatory and pro-angiogenic cytokines such as interleukin 6 and tumour necrosis factors $(\mathrm{TNF})^{(10,11)}$, which mediate inflammatory response and contribute significantly to the formation of subretinal neovascular membranes ${ }^{(6,12-13)}$.

Treatment with anti-angiogenic drugs has been more effective than previous therapies, although the visual prognosis is still limited ${ }^{(14)}$. Therefore, an experimental model that induces the expression of adhesion molecules in the sclera-choroid complex can potentially simulate the changes observed in AMD. Improved understanding of the pathophysiology of AMD might support the development of more effective treatments for the condition.

The objective of this study was to assess ICAM-1 expression in the sclera-choroid complex of hypercholesterolemic rabbits.

\section{Methods}

The study protocol was approved by the Ethics Committee for Animal Research of the Pontifical Catholic University of Paraná, in accordance with the principles of the Declaration of Helsinki (1964) and the Association for Research in Vision and Ophthalmology (ARVO).

\section{Experimental setting}

The procedures described in this study were carried out in the Laboratory of Surgical Technique at PUC-PR and the Study Centre of the Angelina Caron Hospital. Animals were kept in a vivarium (macroenvironment) on 12/12-hour light cycles with air circulation and controlled temperature between 19 and $23^{\circ} \mathrm{C}$. During the experimental period, animals were fed water and standard Nuvital ${ }^{\mathrm{TM}}$ (Nuvital, Colombo, Brazil) rabbit feed ad libitum.

\section{Animals and experimental design}

Twenty-one male New Zealand albino rabbits (Oryctolagus cuniculus) were selected for this study from the Central Vivarium of PUC-PR. The animals had a mean age of 110 days and a mean weight of 2,770 grams. They were divided into two groups: a normal diet group (NG) with 8 rabbits and a hypercho-lesterolemic diet group (HG) with 13 rabbits. NG animals were fed Nuvital $^{\mathrm{TM}}$ (Nuvital, Colombo, Brazil) standard laboratory rabbit feed and euthanised after 4 weeks. Rabbits from the HG group were fed Nuvital $^{\mathrm{TM}}$ (Nuvital, Colombo, Brazil) standard laboratory rabbit feed with additional $1 \%$ cholesterol throughout the study (supplementary feed) and were euthanised after 8 weeks.

Serum total cholesterol, triglycerides, HDL cholesterol, and fasting glucose levels were measured for each rabbit at the baseline and at the time of euthanasia. Blood samples were taken by puncturing the marginal ear vein under general anaesthesia by intramuscular injection of ketamine $5 \mathrm{mg} / \mathrm{kg}$ and xylazine 35 $\mathrm{mg} / \mathrm{kg}$. Plasma levels of glucose, total cholesterol, HDL cholesterol, and triglycerides were determined using the automated enzymatic-colorimetric method (Architect ${ }^{\mathrm{TM}}$, Abbott Diagnostics). A total of 500 microlitres of serum from each animal were frozen for future analysis. The weight of rabbits was measured on a weekly basis.

The animals were euthanised by intravenous injection of 5 $\mathrm{mL}$ pentobarbital and their eyes were immediately fixed in $4 \%$ paraformaldehyde (Merck, Darmstadt, Germany) in a $0.1 \mathrm{M}$ phosphate buffer at $\mathrm{pH} 7.4$ for 4 hours for histomorphometric and immunohistochemical analysis.

\section{Preparation of supplementary feed}

For the $1 \%$ hypercholesterolemic feed used throughout the 8 weeks of the experiment, $200 \mathrm{~g}$ of cholesterol $95 \%$ (SigmaAldrich $^{\mathrm{TM}}$ ) were dissolved in $800 \mathrm{~mL}$ of chloroform (Biotec ${ }^{\mathrm{TM}}$ ) and the solution was uniformly distributed over $20 \mathrm{~kg}$ of Nuvital $^{\mathrm{TM}}$ (Nuvital, Colombo, Brazil) rabbit feed. Before feeding it to the rabbits we waited for 24 hours to allow the chloroform to evaporate. Each animal was offered $600 \mathrm{~g}$ of feed per day ${ }^{(15)}$.

\section{Histomorphometric Analysis (quantitative)}

Both eyes of each animal were removed and fixed, but only one was chosen at random for analysis. After fixation, the samples were evaluated macroscopically. An axial section was performed at the level of the optic nerve, dividing the ocular globe into two equal halves (upper and lower). The lower half was stored for future studies. The upper half was dehydrated, diaphanised and embedded in paraffin using a Leica ${ }^{\mathrm{TM}} \mathrm{TP} 1020$ tissue processor (Leica, Wetzlar, Germany). Paraffin blocks were produced using a Leica ${ }^{\mathrm{TM}} \mathrm{EG} 1160$ embedding station. A Leica ${ }^{\mathrm{TM}}$ RM2145 microtome (Leica, Wetzlar, Germany) was used to obtain 5 - $\mu$-thick histological sections. The sections were placed on glass slides smeared with albumin, stained with haematoxylineosin, and mounted with $24 \times 90-\mathrm{mm}$ coverslips using Entellan 
Mounting Medium, Merck ${ }^{\mathrm{TM}}$ (Merck, Darmstadt, Germany).

For quantitative analysis the selected sections were stained with haematoxylin-eosin and evaluated microscopically with a $4 \mathrm{x}$ objective lens. Using a blue marker, the posterior segment of the half ocular globe was divided manually into 10 equal segments (from one pars plana to the contralateral pars plana). One image was obtained per segment using an Olympus BX50 microscope connected to a Sony camera and Image-Pro Plus ${ }^{\mathrm{TM}}$ software. In each captured image four linear morphometric measurements were taken using the Image-Pro Plus ${ }^{\mathrm{TM}}$ software in order to evaluate scleral and choroidal thickness in the 10 segments. Finally, the mean values of the four measurements in each segment were calculated for all samples. Thickness was expressed in micrometres.

\section{Tissue preparation and immunohistochemical analysis}

The histological cuts were deparaffinised and rehydrated, and then subjected to blocking of endogenous peroxidase. They were subsequently washed in deionised water and incubated in a moist chamber at $95^{\circ} \mathrm{C}$ for 20 minutes for antigen retrieval, after which they were again subjected to blocking of endogenous peroxidase. Sections were covered with primary mouse antiICAM-1 monoclonal antibody diluted at 1:100 Novocastra $^{\mathrm{TM}}$, Newcastle upon Tyne, England). They were then covered with a secondary antibody, HRP-labelled anti-mouse polymer (Advance $^{\mathrm{TM}}$ System, DakoCytomation, Inc., Carpinteria, CA, USA), and incubated at room temperature for 30 minutes. The sections were dripped with mixed DAB substrate (DakoCytomation, Inc., CA, USA) and incubated for another 3 to 5 minutes. Finally, the slices were counterstained with Mayer's haematoxylin and mounted.

Positive and negative controls were used in all markings, and the slides were first analysed by an observer who did not know to which group the slides belonged (masked analysis). In this analysis, positive and negative results for the ICAM-1 marker were recorded. The positive areas acquired a brownish colour and were analysed using colour morphometry. For this procedure, images were captured in five consecutive fields, from the pars plana to the contralateral pars plana, using an Olympus BX50 microscope with a 40x objective lens, a Sony DXC-107A camera, and Image-Pro Plus software. This software allowed the observer to select and colour the positive areas. The immunoreactive surface area was then automatically calculated by the software and expressed in micrometres ${ }^{2}$. Data were compiled in a Microsoft Excel (Redmond, WA, USA) spreadsheet for statistical analysis. The variable immunoreactive area represents the sum of all positive areas in each of the five fields.

\section{Statistical analysis}

To compare groups with regard to the quantitative variables we used either Student's $t$-test for independent samples or the Mann-Whitney nonparametric test, as appropriate. Normality was assessed using the Shapiro-Wilk test. Values with $\mathrm{p}<0.05$ were considered statistically significant. Data were analysed using Statistica 8.0 software.

\section{Results}

Comparing groups with regard to glucose, total cholesterol, HDL, and triglycerides.

Laboratory values in NG (normal diet group) animals remained stable from the baseline to the end of the experiment.
On the other hand, HG (hypercholesterolemic diet group) animals showed a significant increase in total cholesterol at the time of euthanasia. At the baseline, mean total cholesterol levels for both groups were approximately $41.3 \mathrm{mg} / \mathrm{dL}$, and they reached 2146.8 $\mathrm{mg} / \mathrm{dL}(\mathrm{p}<0.001)$ in $\mathrm{HG}$ rabbits at the end of the experiment. Triglyceride levels also changed significantly in $\mathrm{HG}$ rabbits. Mean values at the baseline were approximately $46.5 \mathrm{mg} / \mathrm{dL}$ for both groups, and they reached $168.5 \mathrm{mg} / \mathrm{dL}(\mathrm{p}=0.001)$ in $\mathrm{HG}$ animals at the time of euthanasia. No significant change was observed for glucose and HDL levels in this group at the end of the experiment.

\section{Sclera and choroid staining with haematoxylin-eosin}

Very few histiocytes were found in the sclera-choroid complex of NG animals (Figure 1), whereas HG samples revealed a large number of macrophages in these structures, causing their thickness to increase (Figure 2).

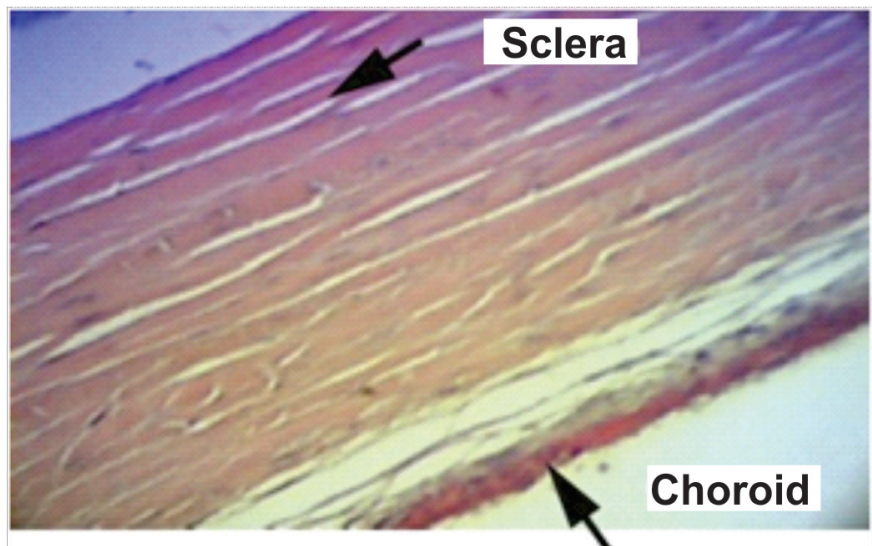

Figure 1. Sclera and choroid of an NG animal. Very few histiocytes can be observed in the sclera and choroid.

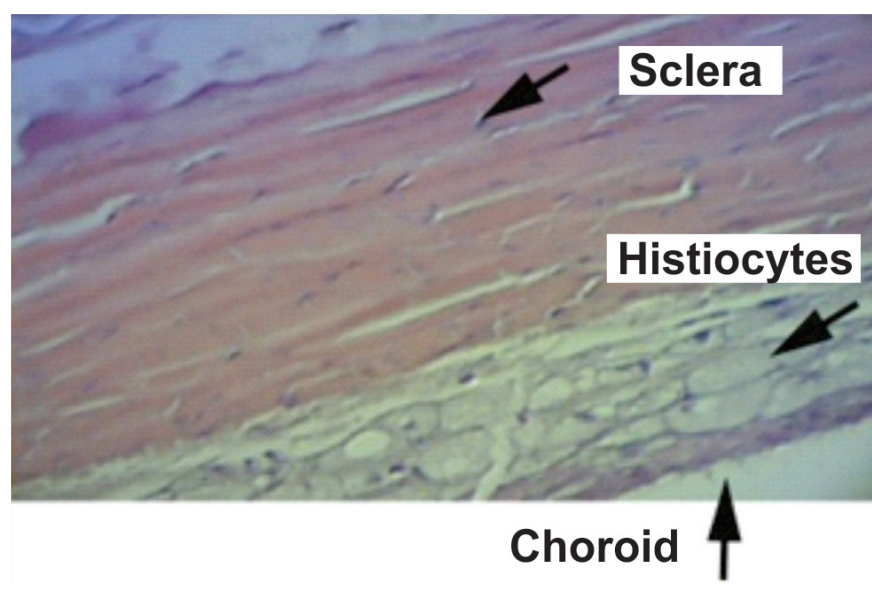

Figure 2. Sclera and choroid of an HG animal. The sclera and choroid are thickened due to the large number of histiocytes.

\section{Comparing groups with regard to scleral-choroidal thickness (morphometry).}

HG animals showed a significant increase in scleralchoroidal thickness relative to NG animals $(\mathrm{p}<0.001)$ (Table 1). 
Table 1

Scleral-choroidal thickness (in micrometres)

\begin{tabular}{|c|c|c|c|c|c|c|c|c|}
\hline Variable & Group & $\mathbf{N}$ & Mean & Median & Minimum & Maximum & $\begin{array}{l}\text { Standard } \\
\text { deviation }\end{array}$ & P Value* \\
\hline $\begin{array}{l}\text { Scleral-choroidal } \\
\text { morphometry }\end{array}$ & GN & 8 & 232,9 & 221,4 & 192,9 & 307,7 & 35,8 & \\
\hline
\end{tabular}

* Student's $t$-test for independent samples, $\mathrm{p}<0.05$.

NG: Normal diet group; HG: Hypercholesterolemic diet group.

Comparing groups with regard to the total ICAM-1immunoreactive area

HG animals showed a significant increase in ICAM-1 expression in the sclera-choroid complex relative to NG animals $(\mathrm{p}<0.001)$ (Table 2), characterised by the brownish colour acquired by immunoreactive areas (Figure 3-B). Conversely, the sclera-choroid of $\mathrm{NG}$ animals was thinner and predominantly blue, indicating low immunoreactivity to anti-ICAM-1 antibodies (Figure 3-A).

Table 2

Total surface area of the sclera-choroid immunoreactive to anti-ICAM-1 antibodies through colour morphometry. Values are expressed in micrometres ${ }^{2}$.

\begin{tabular}{lcccccccc}
\hline Variable & Group & n & Mean & Median & Minimum & Maximum & $\begin{array}{c}\text { Standard } \\
\text { deviation }\end{array}$ & $\begin{array}{c}\text { Palue* } \\
\text { Immunoreactive }\end{array}$ \\
Area & GN & 8 & 607,0 & 218,5 & 50,2 & 2200,4 & 858,7 \\
\hline
\end{tabular}

*Mann-Whitney nonparametric test, $\mathrm{p}<0.05$.

NG: Normal diet group; HG: Hypercholesterolemic diet group.

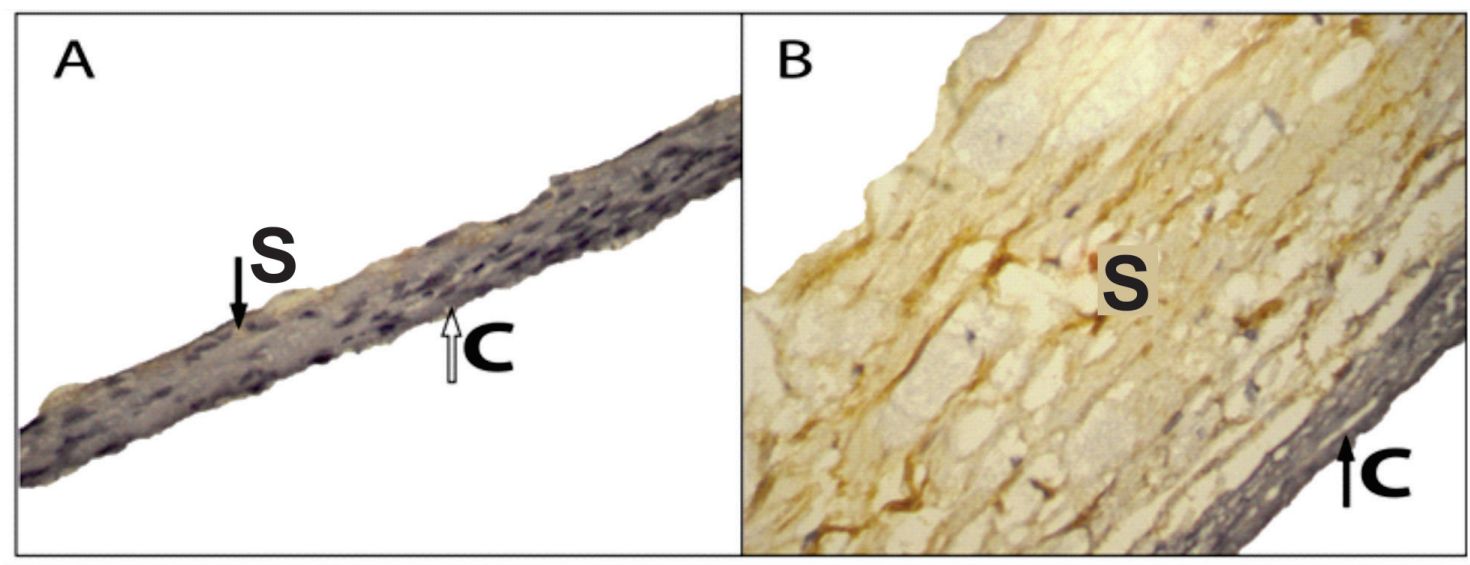

Figure 3. Scleral-choroidal immunoreactivity to anti-ICAM-1 antibodies. A. Sclera-choroid complex of an NG rabbit. The predominantly blue colour indicates low immunoreactivity to ICAM-1. Note the thin sclera and choroid. B. Sclera-choroid complex of an HG rabbit. The predominantly brownish colour indicates high immunoreactivity to ICAM-1. Note the large number of macrophages in the sclera (S). Thickened sclera and choroid. S: Sclera; C: Choroid.

\section{DisCUSSION}

In a recent experimental study, our group demonstrated that a hypercholesterolemic diet increased MCP-1 expression in the sclera and choroid, suggesting that the changes in great vessels that induce atherosclerotic plaque formation might also occur in the sclera-choroid complex ${ }^{(16)}$. After observing an increase in chemotactic molecules such as MCP-1, adhesion molecules had to be assessed to verify the hypothesis that atherosclerosis and AMD have similar pathophysiological mechanisms ${ }^{(17-19)}$.

In a normal eye, immunoglobulin ICAM-1 expression is low in the vascular endothelium of the choroid and retina, as well as the RPE, Bruch's membrane, and the external limiting membrane ${ }^{(20-22)}$. However, under pathological conditions such as exudative AMD, there is a significant increase in ICAM-1 expression in choroidal vessels and RPE cells. This increase in 
immunoreactivity has been observed mainly around the subretinal neovascular membrane (SNM), where a large number of vessels is observed ${ }^{(23)}$. Increased ICAM-1 expression in the RPE and choroid during SNM formation was also observed in experimental studies, suggesting this immunoglobulin is involved in the pathogenesis of $\mathrm{AMD}^{(24-25)}$. This hypothesis was supported by another experiment where mice genetically deficient for ICAM1 or its counter-receptor CD18 were found to be less prone to SNM formation than normal mice(5).

In the present study, a cholesterol-enriched diet induced a significant increase in ICAM-1 expression in the sclera-choroid complex. As it is involved in leukocyte recruitment to inflamed tissues $^{(26)}$, the increased expression of this immunoglobulin may explain the significant rise in the number of macrophages and the consequent increase in scleral-choroidal thickness observed in this and other studies.

Inflammatory cells and the complement system play an important role in the pathogenesis of $\mathrm{AMD}^{(27)}$. Furthermore, it has been demonstrated that macrophages produce inflammatory cytokines, tissue factor, VEGF, and other angiogenic factors ${ }^{(9,28-29)}$. It has also been experimentally observed that the widespread depletion of macrophages decreases SNM activity ${ }^{(30)}$. Hence, there is a consensus regarding the importance of macrophages in the pathogenesis of AMD. In this context, it is worth noting that oxidised LDL is the major stimulus for an increase in chemotactic molecules, adhesion molecules that attract macrophages to the inflammatory site, both in atherosclerosis and in $\mathrm{AMD}^{(31)}$. However, increased ICAM-1 expression is induced not only by oxidised LDL, but also by native LDL $^{(32)}$. Thus, LDL deposited in Bruch's membrane, originating from the degradation of photoreceptor ends by RPE cells ${ }^{(2,31)}$, can potentially increase the expression of these adhesion molecules. This may explain the increased number of macrophages and the onset of AMD. Therefore, experimental models that induce the accumulation of macrophages in the choroid by increasing the number of chemotactic or adhesion molecules may mimic macular degeneration, paving the way for future studies on therapies for the condition.

\section{Conclusion}

This study has demonstrated that increased serum cholesterol levels in an experimental model lead to increased ICAM-1 expression, which may explain the accumulation of macrophages in the sclera-choroid complex. Future research using drugs that interfere with this adhesion molecule may shed light on their possible use in the treatment of AMD.

\section{Acknowledgments}

We would like to thank Prof. Dr. Márcia Olandoski for her support on the statistical analysis of collected data.

\section{REFERENCES}

1. AmbatiJ, Ambati BK, Yoo SH, Ianchulev S, Adamis AP. Age-related macular degeneration: etiology, pathogenesis, and therapeutic strategies. SurvOphthalmol. 2003;48(3):257-93. Review.

2. Veloso CE, Almeida LN, Marco LA, Vianna RN, Nehemy MB. [Importance of genetic polymorphisms in the response to age-related macular degeneration treatment]. Rev Bras Oftalmol.2012;71(3):194-8. Portuguese.
3. Pauleikhoff D, Harper CA, Marshall J, Bird AC. Aging changes in Bruch's membrane. A histochemical and morphologic study. Ophthalmology. 1990;97(2):171-8.

4. ShweikiD, Itin A, Soffer D, Keshet E. Vascular endothelial growth factor induced by hypoxia may mediate hypoxia-initiated angiogenesis. Nature. 1992;359(6398):843-5.

5. SakuraiE, Taguchi H, Anand A, Ambati BK, Gragoudas ES, Miller JW, et al. Targeted disruption of the CD18 or ICAM-1 gene inhibits choroidal neovascularization. Invest Ophthalmol Vis Sci. 2003;44(6):2743-9.

6. CohenT, Nahari D, Cerem LW, Neufeld G, Levi BZ. Interleukin 6 induces the expression of vascular endothelial growth factor. J Biol Chem. 1996;271(2):736-41.

7. van de Stolpe A, van der Saag PT. Intercellular adhesion molecule-1. J Mol Med (Berl). 1996;74(1):13-33. Review.

8. Mullins RF, Skeie JM, Malone EA, Kuehn MH. Macular and peripheral distribution of ICAM-1 in the human choriocapillaris and retina. Mol Vis. 2006;12:224-35.

9. Grossniklaus HE, Ling JX, Wallace TM, Dithmar S, Lawson DH, Cohen $\mathrm{C}$, et al. Macrophage and retinal pigment epithelium expression of angiogenic cytokines in choroidal neovascularization. Mol Vis. 2002;8:119-26.

10. May LT, Ghrayeb J, Santhanam U,Tatter SB, Sthoeger Z, Helfgott DC, et al. Synthesis and secretion of multiple forms of beta 2-interferon/Bcell differentiation factor $2 /$ hepatocyte-stimulating factor by human fibroblasts and monocytes. J Biol Chem. 1988;263(16):7760-6.

11. Oh H,Takagi H, Takagi C, Suzuma K, Otani A, Ishida K, et al. The potential angiogenic role of macrophages in the formation of choroidalneovascular membranes. Invest Ophthalmol Vis Sci. 1999;40(9):1891-8

12. Markomichelakis NN, Theodossiadis PG, Sfikakis PP. Regression of neovascular age-related macular degeneration following infliximab therapy. Am J Ophthalmol. 2005;139(3):537-40.

13. Shi X, Semkova I, Müther PS, Dell S, Kociok N, Joussen AM. Inhibition of TNF-alpha reduces laser-induced choroidal neovascularization. Exp Eye Res. 2006;83(6):1325-34

14. Garcia Filho CA, Penha FM, Garcia CA. [Wet-amd treatment: a review in the anti-vegf drugs]. Rev Bras Oftalmol.2012;71(1):63-9. Portuguese.

15. Sun YP, Lu NC, Parmley WW, Hollenbeck CB. Effects of cholesterol diets on vascular function and atherogenesis in rabbits. ProcSocExpBiol Med. 2000;224(3):166-71.

16. Torres RJ,Noronha Ld, Casella AM, LumikoskiTI, Précoma LB,Torres $\mathrm{CL}$, et al. [Increase of choroidal and scleral MCP-1 expression in hypercholesterolemia experimental model]. Arq Bras Oftalmol. 2012;75(1):48-52. Portuguese.

17. Friedman E. A hemodynamic model of the pathogenesis of age-related maculardegeneration. Am J Ophthalmol. 1997;124(5):677-82.

18. Friedman E. The role of the atherosclerotic process in the pathogenesis of age-related macular degeneration. Am J Ophthalmol. 2000;130(5):658-63. Review.

19. Jonas JB, Tao Y, Neumaier M, Findeisen P. [Monocyte chemoattrac-tant protein 1 , intercellular adhesion molecule 1 , and vascular cell adhesion molecule 1 in exudative age-related macular degeneration]. Arch Ophthalmol. 2010;128(10):1281-6. Portuguese.

20. DuguidIG, Boyd AW, Mandel TE. Adhesion molecules are expressed in the human retina and choroid. Curr Eye Res. 1992;11 Suppl:153-9.

21. ElnerSG,Elner VM,Pavilack MA, Todd RF 3rd, Mayo-Bond L,Franklin WA, et al. Modulation and function of intercellular adhesion molecule-1 (CD54) on human retinal pigment epithelial cells. Lab Invest. 1992;66(2):200-11.

22. McLeod S, Lefer DJ, Merges C, Lutty GA. Enhanced expression of intracellular adhesion molecule- 1 and P-selectin in the diabetic human retina and choroid. Am J Pathol. 1995;147(3):642-53.

23. Yeh DC, Bula DV, Miller JW, Gragoudas ES, Arroyo JG. Expression of leukocyte adhesion molecules in human subfoveal choroidalneo vascularmembranes treated with and without photodynamic therapy. Invest Ophthalmol Vis Sci. 2004;45(7):2368-73. 
24. Nagai N, Oike Y, Izumi-Nagai K, Urano T, Kubota Y, Noda K, et al. Angiotensin II type 1 receptor-mediated inflammation is required for choroidal neovascularization. ArteriosclerThrombVasc Biol. 2006;26(10):2252-9.

25. Shen WY, Yu MJ, Barry CJ, Constable IJ, Rakoczy PE. Expression of cell adhesion molecules and vascular endothelial growth factor in experimental choroidalneovascularisation in the rat. Br J Ophthalmol. 1998;82(9):1063-71.

26. van de Stolpe A, van der Saag PT. Intercellular adhesion molecule-1. J Mol Med (Berl). 1996;74(1):13-33. Review.

27. PenfoldPL, Provis JM, Billson FA. Age-related macular degeneration: ultrastructural studies of the relationship of leucocytes to angiogenesis. Graefes Arch ClinExpOphthalmol. 1987; 225(1):70-6.

28. Tsutsumi C, Sonoda KH, Egashira K, Qiao H, Hisatomi T, Nakao S, et al. The critical role of ocular-infiltrating macrophages in the development of choroidal neovascularization. J Leukoc Biol. 2003;74(1):25-32.

29. Zhou J, Pham L, Zhang N, He S, Gamulescu MA, Spee C, et al. Neutrophils promote experimental choroidal neovascularization. Mol Vis. 2005;11:414-24.
30. Sakurai E, Anand A,Ambati BK, van Rooijen N,Ambati J. Macrophage depletion inhibits experimental choroidal neovascula-rization. Invest Ophthalmol Vis Sci. 2003;44(8):3578-85.

31. Ruberti JW, Curcio CA, Millican CL, Menco BP, Huang JD, Johnson M. Quick-freeze/deep-etch visualization of age-related lipid accumulation in Bruch's membrane. Invest Ophthalmol Vis Sci. 2003;44(4):1753-9.

32. Smalley DM, Lin JH, Curtis ML, Kobari Y, Stemerman MB, Pritchard KA Jr. Native LDL increases endothelial cell adhesiveness by inducing intercellular adhesion molecule-1. ArteriosclerThrombVasc Biol. 1996;16(4):585-90.

\section{Corresponding author:}

Rogil José de Almeida Torres

Rua Emiliano Perneta 390; conj 1407

E-mail: rjat@terra.com.br 